\title{
A economia monetária de Cantillon e o debate moderno entre ortodoxia e heterodoxia *
}

\author{
André Roncaglia de Carvalho ** \\ João Machado Borges Neto ${ }^{* * *}$
}

\begin{abstract}
Resumo
O artigo retoma a contribuição de Richard Cantillon à ciência econômica no século XVIII. Apesar de distante no tempo, o arcabouço analítico do autor proporciona reflexões importantes acerca dos fenômenos monetários contemporâneos. Um dos elementos mais significativos é a consideração do ponto de injeção da moeda na economia, permitindo uma compreensão minimamente adequada da relação entre os chamados lados monetário e real da economia. Cantillon já fazia, portanto, uma crítica ao postulado quantitativista, o qual estabelecia uma relação de proporcionalidade entre moeda e preços. Como consequência de sua análise, fica claro que o aumento da quantidade de moeda gera efeitos reais duradouros na economia.
\end{abstract}

Palavras-chave: Economia monetária; Richard Cantillon (1680?-1734); Teoria quantitativa da moeda; Neutralidade da moeda.

\section{Abstract \\ Cantillon's monetary economics and the modern controversy between orthodox and heterodox economists}

The paper discusses the fundamental aspects of Richard Cantillon's monetary ideas throughout the 18th century. However remote in time, the author's analytical framework offers important and useful reflections concerning contemporary monetary phenomena. One of the most significant features in his approach is the theoretical guideline which states that the point of injection of money into the economy should be taken into consideration in order to adequately comprehend the connection between the monetary and real sides of the economy. Therefore, Cantillon already provided a critical appraisal of the incipient quantitative postulate, which stated a proportionate relationship between money and prices. As a consequence of his analysis, it is clear that the increase in the quantity of money generates lasting real effects on the economy.

Keywords: Monetary economy; Richard Cantillon (1680?-1734); Quantity theory of money; Neutrality of money. JEL B11.

\section{Introdução}

O papel da moeda na economia tem sido objeto de extensa e duradoura controvérsia. As diferentes interpretações acerca das funções da moeda, que vão desde considerá-la mera facilitadora das trocas até identificá-la como importante indutora da motivação dos indivíduos, acirram ânimos tanto no debate teórico quanto nas discussões das políticas econômicas dos governos. As experiências de inflações persistentes em numerosas nações por todo o mundo

\footnotetext{
* Artigo recebido em 16 de setembro de 2016 e aprovado em 15 outubro de 2017.

${ }^{* *}$ Professor Adjunto do Departamento de Economia da Escola Paulista de Política, Economia e Negócios (EPPEN) da Universidade Federal de São Paulo (Unifesp), Osasco, SP, Brasil. Contato: andre.carvalho@unifesp.br.

${ }^{* * *}$ Professor do Departamento de Economia e do Programa de Estudos Pós-Graduados em Economia Política da Pontifícia Universidade Católica de São Paulo (PUC/SP), São Paulo, SP, Brasil. Contato: jmborges@ pucsp.br.
} 
trouxeram estas divergências ao primeiro plano, e a ocorrência nos últimos anos de crises cambiais e financeiras tem ampliado as preocupações com a estabilidade do sistema econômico global, salientando-se o funcionamento da organização monetária como um dos seus pilares de sustentação.

Uma forma relevante de organizar as ideias referentes a esse tema é tomar como base um conceito que divide opiniões, a saber, a neutralidade da moeda, isto é, a negação de que variáveis monetárias possam ter (pelo menos em longo prazo) efeitos reais sobre a atividade econômica. Esta concepção vincula-se à adoção de alguma versão da Teoria Quantitativa da Moeda (TQM). A aceitação de ambas pode ser uma referência básica para classificar atualmente uma abordagem como ortodoxa, e a sua negação, como heterodoxa (Mollo, 2004) ${ }^{1}$. Todavia, a relação entre neutralidade da moeda e a TQM merece uma qualificação.

Com o desenvolvimento da forma clássica ${ }^{2}$ da TQM no início do século XX (principalmente com as abordagens de Irving Fisher e da escola de Cambridge) e das visões teóricas gerais correspondentes, a ciência econômica dividia-se em duas teorias: a teoria real (ou pura) e a teoria monetária. A primeira analisava os fenômenos econômicos apenas a partir das chamadas "variáveis reais". A segunda contemplava a influência da moeda sobre os preços, buscando explicações para os fenômenos da inflação e da deflação de preços. Essas teorias se desenvolveram de formas e em ritmos diferentes, sedimentando uma divisão das tarefas explicativas de acordo com a dimensão do problema econômico em questão.

No contexto dessa separação de tarefas, a conclusão central da TQM pode ser resumida com o "teorema da proporcionalidade", que postula haver uma relação direta entre quantidade de moeda e preços, sem que o "lado real" da economia sofra alterações duradouras. Admitiase que uma mudança na quantidade de moeda poderia provocar variações reais no curto prazo; com o tempo, no entanto, elas desapareceriam, e permaneceriam apenas os efeitos sobre os preços, isto é, de natureza monetária. Assim, haveria, segundo esse teorema, uma relação proporcional entre o aumento na quantidade de moeda e a elevação dos preços no longo prazo. Uma das características desta abordagem, portanto, é focar o nível geral de preços, e não dar a devida atenção a variações dos preços relativos; esta questão terá uma importância central neste estudo.

Estas características gerais da abordagem da TQM começaram a ser desenvolvidas desde o século XVI, e tiveram uma exposição clássica pelo menos com as obras econômicas de David Hume, no século XVIII. Como fica claro pelo exposto acima, elas já implicam a ideia de "neutralidade da moeda". No entanto, o uso deste conceito propriamente é bem mais recente. Don Patinkin (1989) atribui o início de seu uso a economistas alemães e holandeses, escrevendo

(1) Mollo destaca também o vínculo destas concepções com a Lei de Say.

(2) Note-se que a forma "clássica" da TQM foi atingida já no período de predomínio do pensamento neoclássico. Na teoria monetária, a continuidade do pensamento entre a Escola Clássica propriamente dita e a Escola Neoclássica foi muito maior do que em outros campos da ciência econômica. Esta foi certamente uma das razões que levaram Keynes, mais preocupado com a discussão de aspectos da economia relacionados com a moeda do que, por exemplo, com a teoria do valor e da distribuição, a incluir sob a designação "clássicos" tanto os clássicos quanto os neoclássicos. 
na primeira década após a I Guerra Mundial, e a sua difusão, a partir do seu emprego em língua inglesa, a Hayek, com a publicação de Prices and Production em 1931 (Hayek, [1931] 1935).

O que pretendemos mostrar neste estudo é que Richard Cantillon (1680?-1734), no seu Ensaio sobre a Natureza do Comércio em Geral, embora utilize (e desenvolva) elementos da TQM, realizou uma análise integrando os efeitos reais das variáveis monetárias, que vai muito além da TQM, e se afasta do "teorema da proporcionalidade" e da concepção de neutralidade da moeda. Aos olhos de hoje, assim, ele desenvolveu elementos de uma teoria monetária heterodoxa ${ }^{4}$.

Além da atualidade de seu pensamento, Cantillon se destaca pela didática de seu argumento, sem que isto implique prejuízo para a sua precisão. Com seu trabalho, uma concepção que, para os padrões atuais deve ser considerada heterodoxa, ganhou um argumento original: a ideia de que a maneira pela qual a moeda entra no sistema é essencial para compreender seus efeitos sobre a produção e o comércio ${ }^{5}$. Em particular, Cantillon destacou os efeitos das diversas formas de introdução da moeda no sistema sobre os preços relativos e sobre as taxas de juros. A existência deste impacto diferenciado tem sido chamada, com razão, de "Efeito Cantillon" (Blaug, 1989, v. I, p. 56).

A análise monetária de Cantillon está, portanto, muito longe da tendência persistente entre os adeptos da TQM de focar apenas o nível geral de preços. Pelo contrário, ele chamou a atenção para o fato de que uma variação no nível geral de preços implica também variações nos preços relativos. Mark Blaug chega a dizer que o abandono desta percepção mais ou menos desapareceu da ciência econômica até ser revivida por Mises e Hayek nos anos 30 do século XX. Teria havido, assim, um "desleixo analítico quase indescritível" na teoria monetária por cerca de duzentos anos (Blaug, 1995, p. 43) .

Como ilustração da atualidade dessa questão, voltou-se a discutir recentemente sobre as limitações dos índices de preço como indicadores da atividade econômica (Laidler, 2006; Kiyotaki, 2006; Blanchard, 2006). White (2006, p. 7) salienta a falha do índice de preços em captar os movimentos internos da economia, citando como a recessão japonesa, iniciada na década de 1990, foi precedida por um substancial crescimento do crédito, dos preços dos ativos, dos investimentos e da desregulamentação do setor financeiro. Por fim, o autor cita a recente crise financeira no sudeste asiático, ressaltando que não foram percebidas pressões inflacionárias anteriormente à irrupção da crise. Ao contrário, como no caso do Japão recente

(3) Hayek, ao utilizar o conceito de "neutralidade da moeda", atribui a primazia de seu uso moderno a Wicksell, o que é incorreto, segundo Patinkin.

(4) Naturalmente, na época de Cantillon, em que os elementos fundamentais da atual ortodoxia ainda não se haviam desenvolvido (mesmo que a formulação da TQM já estivesse em andamento), e em que predominavam ideias mercantilistas, ele não seria considerado heterodoxo. A própria distinção entre ortodoxos e heterodoxos, aliás, não existia.

(5) O que contrasta claramente com análises como a de Friedman, cuja falta de atenção para esta questão levou-o a usar a imagem da moeda "jogada por helicóptero", mencionada adiante.

(6) "Desleixo analítico", aqui, é a tradução de "analytical sloppiness".

(7) Em sua História do Pensamento Econômico, Blaug relaciona o "Efeito Cantillon" com a discussão feita por Keynes da “difusão do nível de preços” no Capítulo 7 de seu Treatise on Money (1930) (Blaug, 1989, v. I, p. 56). 
e dos EUA do início do século XX, o crédito se expandia, os preços dos ativos cresciam e a formação bruta de capital fixo se fortalecia.

O artigo está dividido em três seções, além dessa introdução. A primeira seção apresenta os fundamentos da teoria quantitativa da moeda, apoiando-se nas versões mais difundidas da escola de Cambridge e de Irving Fisher, de forma a ilustrar, pela diferença, os pontos centrais da abordagem de Cantillon, os quais são analisados na segunda seção. Seguindo-se as considerações finais.

\section{A ortodoxia e o problema da integração: a relação direta entre a moeda e os preços}

Desde os seus primórdios, o foco da teoria monetária tem sido a estabilidade dos preços (Eltis, 1995). Na abordagem predominante, a moeda tinha como função facilitar o livre fluxo de mercadorias, de forma a dinamizar o comércio. Por isso, um sistema saudável de trocas monetizadas era tido como uma condição sine qua non para o desenvolvimento econômico e para o funcionamento do lado real da economia. Era da alçada da teoria monetária debater propostas de instituições monetárias que promovessem o funcionamento eficiente da economia real. A instabilidade do nível de preços reduzia a eficiência da moeda como unidade de conta - isto é, padrão de valor - e, por estar recorrentemente associada aos pânicos e crises financeiras, como meio de troca. A moeda de valor instável impedia o bom funcionamento do mercado, uma vez que distorcia o sistema de preços, gerando desequilíbrios e rigidezes na circulação de mercadorias. Daí decorre a associação da teoria monetária do nível de preços à escola clássica, e a seus sucessores neoclássicos (Blaug, 1995, p. 28; Laidler, 1991, p. 32-40). A relação entre moeda e preços figurava, portanto, como questão central para a teoria monetária clássica (Laidler, 1991, p. 9).

Até a primeira guerra mundial, a teoria monetária passou por grandes refinamentos teóricos. Os responsáveis por essa evolução estavam teoricamente comprometidos com o desenvolvimento da teoria quantitativa da moeda, a saber: a escola de Cambridge, representada principalmente por Alfred Marshall e A. C. Pigou, e Irving Fisher, da Universidade de Yale, nos EUA. Para esta teoria monetária, de cunho neoclássico, a explicação do comportamento do nível de preços permanecia como problema central a ser tratado. Os desenvolvimentos promovidos pela Escola de Cambridge e por Fisher foram traduzidos em maiores graus de clareza e refinamento teóricos. Adicionalmente, os autores neoclássicos adaptaram a doutrina clássica a uma nova estrutura institucional, a saber, o sistema bancário comercial moderno. Neste cenário, receberam redobrada atenção as diferentes formas de moeda, tais como o crédito e os depósitos bancários. Mesmo assim, esses fatores foram inseridos na análise sem transformar, de maneira significativa, o quadro analítico quantitativista ${ }^{8}$.

(8) A síntese de Soromenho (1995, p. 58) é bastante ilustrativa, dizendo o autor que, no início dos anos 1930, consideravase "[...] que existia um relativo atraso no campo das investigações monetárias. Isto seria devido à prática, que se tornava cada vez mais frequente, de explicar a determinação do nível de preços unicamente por meio da identificação do volume de moeda existente na economia. Consequentemente, as variações do índice de preços eram atribuídas, sem maiores fundamentos, às alterações da quantidade de moeda. Estabelecia-se, desse modo, uma relação causal direta entre moeda e preços sem que fosse explicado como a moeda poderia ter os efeitos perturbadores de curto-prazo que lhe eram imputados". 
É necessário, portanto, descrever como a teoria quantitativa expõe a relação entre os lados monetário e real da economia, sua fundamentação teórica e o grau de adequação desta proposição à realidade econômica. Por meio desse expediente, busca-se um contraste mais evidente desta abordagem com as ideias de Cantillon.

Em sua forma geral, a teoria quantitativa da moeda postulava que o nível de preços se ajustaria eventualmente a uma variação na quantidade de moeda por meio de mecanismos diretos e indiretos de transmissão. Daí resultaria a equalização entre valor real do estoque monetário nominal $M$, isto é $M / P$, à demanda real pela moeda, definida pela fração $1 / V$ do volume real de transações $T$ que o público desejasse manter na forma de encaixes reais. Logo, a teoria quantitativa da moeda - expressa na equação $M / P=T / V$ - sugeria uma abordagem em termos de oferta e demanda para o fenômeno. A expressão "se ajustaria eventualmente" corrobora o teorema da proporcionalidade, isto é, a ideia de que a quantidade de moeda e os preços absolutos sofreriam, no longo prazo, variações proporcionais, deixando inalterados os preços relativos (isto é, o preço de um bem em termos de um outro bem) e o nível de produção.

Para que tal fenômeno se desenrole dessa maneira, é necessário que haja uma distribuição proporcional da quantidade de moeda adicionada à economia. Assim, a relação de proporcionalidade entre moeda e preços no curto prazo depende da forma precisa pela qual a moeda é injetada na economia. Pode-se contornar o problema de distinguir os diferentes efeitos da moeda sobre a economia, a partir de determinado ponto de injeção, por meio da suposição de que os saldos monetários de todos os indivíduos são incrementados na mesma proporção. À guisa de ilustração, e seguindo a sugestão de Friedman, pode-se imaginar que um helicóptero, voando sobre a economia, deixe cair a quantidade adicional de moeda, distribuindo-a proporcionalmente entre todos os indivíduos (Patinkin, 1989, p. 278). Postulando-se a dicotomia clássica, isto é, a ideia de que a variação nos saldos monetários não influencia as preferências e os gostos dos indivíduos (definidos no lado real), tem-se que um aumento na quantidade de moeda seria repassado automaticamente para os preços das mercadorias. Abordando a mesma questão por outro lado, se todos os preços e saldos monetários nominais iniciais forem dobrados, e a demanda por saldos reais não for afetada, deve haver uma demanda dobrada por saldos monetários. Essa é a definição da elasticidade unitária da demanda nominal por moeda (Patinkin, 1965, p. 28-29).

No caso de a economia se encontrar em estado de equilíbrio de longo prazo, o teorema se sustenta independentemente da forma pela qual a quantidade de moeda adicional é distribuída, pois se supõe que o sistema se ajusta automaticamente em seu lado real e os efeitos monetários são completamente repassados para os preços. Vale ressaltar, entretanto, que isso ocorre somente sob essas estritas condições (Patinkin, 1965, p. 29; Patinkin, 1995, p. 125) ${ }^{9}$.

(9) No que diz respeito ao curto prazo, tanto para os economistas clássicos, quanto para os neoclássicos, o lado real da economia sofria ajustes até que, no longo prazo, o excesso de demanda por bens, gerado pelo aumento na moeda e mantidas constantes as condições do lado real, fosse ajustado pelos preços monetários das mercadorias na mesma proporção do aumento inicial na quantidade de moeda. (Patinkin, 1965, p. 162-169). Aceitava-se, portanto, que o impacto no lado real da economia poderia ser explicado pela existência de rigidezes nos preços, nos salários nominais, na taxa nominal de juros, nas cobranças contratuais de aluguéis e impostos; concentração de poder de mercado, conflitos distributivos entre grupos organizados etc. (Laidler, 1991, cap. 4). 
A teoria quantitativa da moeda pode ser apresentada na forma da equação de troca, a qual costuma ser apresentada em duas versões básicas. Uma delas é a da Escola de Cambridge. Conhecida como a abordagem da demanda por encaixes reais, essa versão tem a seguinte forma: $M=k P Y$, onde a constância de $k$ sugere que a elasticidade da demanda por moeda é igual a 1 , o que permite demonstrar o teorema da proporcionalidade entre a moeda e os preços. A segunda versão é a elaborada por Irving Fisher, para o qual a equação de troca tem o seguinte formato estilizado: $M V=P T$. Assim, o valor de transações totais da economia, definido por $P T$, é igual ao montante de meio circulante na economia, dado por $M V^{10}$. Essa é conhecida como a abordagem da demanda por transações, na qual a velocidade de circulação da moeda é constante e as transações são determinadas por variáveis reais independentes, resultando logicamente na transmissão proporcional dos efeitos do aumento na quantidade de moeda sobre o nível de preços (Blaug, 1995, p. 33-35).

Marshall buscava demonstrar os efeitos de mudanças na demanda por moeda sobre o nível de preços de equilíbrio da economia. Para tanto, o comportamento da taxa de juros era elemento crucial em sua análise. Em termos gerais, o processo de transmissão se dá na seguinte ordem: um aumento na quantidade de moeda eleva a disponibilidade de recursos emprestáveis, incrementando a quantidade de capital sob comando daqueles cuja atividade é emprestar dinheiro para outros indivíduos. $\mathrm{O}$ aumento na quantidade de credores em relação à quantidade de devedores reduz a taxa de juros. A velocidade da queda na taxa de juros depende das oportunidades de investimento desses recursos na indústria e no comércio. Em não havendo oportunidades em número e volume suficientes, os detentores dessa soma adicional de dinheiro não têm alternativa senão emprestá-la a uma taxa de juros. Esses recursos serão utilizados pelos devedores na compra de bens no mercado, pressionando os preços para cima (Laidler, 1991, p. 67-68).

Era amplamente aceito que, apesar de diferenças no estilo de demonstração da teoria, as abordagens de Cambridge e de Irving Fisher diziam a mesma coisa. Deve-se atentar para o fato de que o comportamento do nível de preços era um efeito, e não uma causa, do comportamento de outras variáveis na equação de troca. Com isso, define-se a direção da transmissão: indo da quantidade de moeda para preços; o efeito contrário não poderia ser analisado pela teoria quantitativa, como ressalta Laidler (1991, p. 78).

O truísmo representado pela equação de troca ganha sentido ao se isolarem das relações entre as variáveis os fatores determinantes da velocidade e do volume de transações. Em outros termos, as variáveis $V$ e $T$ são independentes da quantidade de moeda e de depósitos da economia. Com isso, o lado monetário da economia é separado do lado real, tornando direta a transmissão de um aumento na quantidade de moeda para o nível de preços.

(10) A versão original da equação de Fisher traz um detalhe importante sobre a visão do autor. Desenvolvida na forma de $M V+M^{\prime} V^{\prime}=\Sigma p Q=P T$, a equação tem que $M$ é moeda (papel e metal), $M^{\prime}$ são depósitos à vista, os $V$ 's são as respectivas velocidades de circulação, $p$ é o preço de qualquer bem transacionado, $Q$ é a quantidade. Por fim, tem-se que $P$ é o nível geral de preços - isto é, um índice dos $p$ 's - e $T$ representa o volume de transações - um índice de $Q$ (Fisher, 1963, cap. 2 e 3, p. 8-54). 
Vale atentar-se para a especificidade do mecanismo de transmissão tal qual apresentado por Fisher. Suponha-se que se dobre a quantidade de moeda em uma economia. Estando os preços inalterados, um agente detém agora o dobro da quantidade de moeda que ele costuma manter em mãos. Ele buscará se livrar desse excesso de dinheiro, comprando bens. Assim que alguém se dispuser a aceitar seu dinheiro, tem-se que essa transferência não altera o montante de moeda da comunidade, observando-se o efeito de tão-somente aumentar o excedente de outra pessoa. Em decorrência, todas as pessoas têm mais dinheiro em mãos do que sua experiência e sua conveniência sugerem manter. Fisher postula que todas as pessoas trocarão esse dinheiro adicional, e relativamente inútil, por outros bens. Esse aumento generalizado na demanda por bens eleva todos os preços da economia.

O economista norte-americano estava preocupado, todavia, com a relação de longo prazo entre moeda e preços; mais exatamente com uma medida específica dos preços, a saber, o nível de preços. Como ele deixa claro, a relação entre os preços individuais (ou preços relativos) fica de fora da análise. Não obstante, ele alega haver uma compatibilidade entre as teorias dos preços relativos e aquelas explicações fundadas sobre a teoria quantitativa ${ }^{11}$. Mas como? Em linhas gerais, a teoria quantitativa optava por olhar somente para o longo prazo, advogando que os estímulos ao comércio e à indústria seriam esgotados pela ação dos mecanismos de mercado, transmitindo os efeitos inteiramente aos preços. A maneira pela qual a moeda entra na economia não teria, portanto, muita importância; tampouco era atraente a esses teóricos analisar os efeitos de curto prazo, dadas as condições de desequilíbrio. Cumpria tão-somente a função de estabelecer a ligação lógica entre dois pontos de equilíbrio: antes e depois da variação na quantidade de moeda.

Assim, de maneira esquemática, a teoria quantitativa da moeda deve conter as três proposições que a compõe, a saber: (1) há uma causalidade entre a moeda $(M)$ e os preços $(P)$; (2) há uma demanda estável por papel-moeda; (3) a velocidade de circulação da moeda ( $V$ ) é tida como sendo constante; e (4) o volume de transações ( $T$, na abordagem de Fisher), ou o volume do produto ( $Y$, na abordagem de Cambridge), é determinado por fatores reais tais como dotações, preferências e tecnologia - ou seja, independentemente da quantidade de moeda ou do nível de preços (Blaug, 1995, p. 29).

Para o estudo que realizamos aqui, é importante destacar que este paradigma monetário apresentava dois problemas centrais ${ }^{12}$. O primeiro era o estabelecimento de relações causais diretas entre agregados (volume de transações, demanda por moeda, velocidade de circulação,

(11) "It would take us too far afield to insert here a complete statement of price-determining principles. But the compatibility of the equation of exchange with the equations which have to deal with prices individually may be brought home to the reader sufficiently for our present purposes by emphasizing the distinction between (1) individual prices relatively to each other and (2) the price level. The equation of exchange determines the latter (the price level) only, and the latter is the subject of this book. [...] It should be clearly recognized that price levels must be studied independently of individual prices" (Fisher, 1963, p. 175 - grifos do autor - negritos nossos).

(12) Naturalmente, há diversos outros problemas que podem ser apontados, começando com a questão da visão muito restrita do papel da moeda na economia (fundamentalmente, a de facilitadora das trocas). Entretanto, dado o objetivo limitado que temos nesta apresentação da TQM - contrastá-la com a abordagem de Cantillon - os dois problemas citados são os mais relevantes. 
quantidade de moeda e nível geral de preços), resultando na pouca importância dada ao comportamento dos indivíduos ${ }^{13}$. Em segundo lugar, como reconheceu Soromenho (1995, p. 59), a teoria não dava ênfase aos diferentes e possíveis caminhos pelos quais poderia a moeda entrar em circulação.

Como decorrência dessa estrutura analítica, associavam-se eventos numa causalidade fortemente apoiada em levantamentos empíricos de longo prazo. Um exemplo disso é a relação positiva (de longo prazo), estatisticamente comprovada, entre nível de preços e produção (Friedman; Schwartz 1963). Quando os preços sobem, percebe-se um movimento de aquecimento da produção; o mesmo ocorrendo no sentido contrário. Portanto, não há controvérsia sobre a correlação empírica entre as variáveis retratadas pela equação de trocas, qual seja, entre a renda nominal $(P Y)$ e fluxo de moeda $(M V)$. O ponto fulcral da disputa reside na decomposição da renda nominal em $P$ e $Y$ (Blaug, 1995, p. 41-42). A teoria quantitativa assevera que uma elevação em $M$ inicialmente afeta $P Y$ (efeitos de primeira ordem), mas eventualmente $\mathrm{P}$ absorve todo o efeito de um estoque de moeda maior (efeitos de segunda ordem). Não se especifica, contudo, a duração desta transição entre o curto e o longo prazo, tal como nas "defasagens longas e variáveis" da política monetária, segundo Friedman (1961).

Mesmo dentro dos marcos gerais deste paradigma, ficava evidente para alguns economistas a necessidade de se explorarem mais profundamente os efeitos perturbadores de curto prazo das variações na quantidade de moeda sobre a estrutura produtiva da economia, uma vez que postular a relação entre os eventos não dava conta de explicar as forças que os colocavam em movimento. Ou seja, dever-se-ia analisar antes a passagem $M \rightarrow P Y$ para, então, poder concluir $M \rightarrow(P Y \rightarrow) P$. É nesse sentido que as análises de curto prazo e de longo prazo podem ser complementares.

Tais esforços foram conduzidos por uma série de economistas ao longo do século XIX e XX. Dentre eles, podemos destacar, nesse tocante, os trabalhos de Henry Thornton ([1802] 1939) e John Stuart Mill (1808); Knut Wicksell ([1898] 1965 e [1906] 1988) e Gunnar Myrdal ([1932] 1965), da escola sueca; de John Maynard Keynes ([1930] 1973), Dennis H. Robertson ([1926] 1949) e A.C. Pigou ([1927] 1929) de Cambridge; de Ludwig Von Mises (1978) e Friedrich von Hayek ([1931] 1933) da escola austríaca. No entanto, o que nos interessa aqui é apreciar a obra de um economista anterior a todos os citados, que tratou o tema com uma sensibilidade científica especial.

\section{Os fundamentos da divergência: preços relativos e ponto de injeção da moeda}

A vida de Richard Cantillon é marcada por mistérios, rumores e uma suposta tragédia terminal. Isso certamente não pode ser atribuído ao conteúdo seu trabalho, o qual é marcado

(13) Vale lembrar que na teoria de Fisher apresentada anteriormente, a atribuição dos "hábitos do indivíduo" como elemento determinante da velocidade de circulação da moeda tem importância relativa. Isso se explica pela sua suposição de que a velocidade de circulação é constante. Portanto, apesar de ser um indício da aplicação do comportamento do indivíduo, a relevância dessa variável na explicação fornecida pela teoria quantitativa da moeda deve ser qualificada. 
pela lucidez e abrangência do tratamento da natureza do comércio em geral, apresentada em seu livro Essai sur la nature du commerce en général (Cantillon, 1931, 2002), escrito entre as décadas de 1720 e 1730 e publicado em $1755^{14}$.

Várias foram as interpretações e as classificações dadas à obra de Cantillon, conforme salienta Bordo (1983, p. 236). Dentre eles, alguns economistas de destaque, como Jevons (1881), o qual observou que o Ensaio de Cantillon foi o primeiro tratado sistemático de Economia e sugeriu ainda que o Ensaio poderia ser considerado o "berço da Economia Política", afirmação compartilhada por Hayek (1991, p. 246) e alguns autores da escola austríaca $^{15}$.

Cantillon também é disputado como um precursor da escola monetarista, sendo-lhe atribuída não apenas uma adesão estrita à TQM como a própria paternidade da "abordagem monetária do balanço de pagamentos" (Bordo, 1983, p. 241-247). A caracterização de Cantillon como "monetarista", aliás, é feita também por Antoin Murphy, para quem a contraposição entre John Law e Cantillon corresponderia a um Keynes (Law) e a um monetarista (Cantillon) setecentistas (Murphy, 1984, p. 53). Todavia, associações tão estritas de um autor do início do século XVIII com teorias econômicas do século XX têm certamente muito de artificial. Pesquisas recentes com traduções revisadas do Essai, como as de Groenewegen (2012), Van den Berg (2012a e 2012b) e Sabbagh (2016), têm apontado que a classificação de Cantillon como precursor de teorias modernas incorre em diversos problemas de consistência e coerência. É particularmente problemática a associação de Cantillon ao moderno monetarismo, como destaca Van den Berg (2012a, p. 58-64) e como procuraremos mostrar em seguida de forma mais detalhada ${ }^{16}$.

(14)Há uma controvérsia de razoável amplitude acerca dos problemas enfrentados por Cantillon para publicar seu livro por conta da censura real, adicionando-se às distorções que o texto sofreu ao ser traduzido. Dado o escopo estritamente monetário do presente artigo, remetemos o leitor aos escritos de pesquisadores que vêm se dedicando à vida e à obra de Cantillon. Dentre eles, destacamos as biografias de autoria de Murphy (1986) e Brewer (1992), bem como os artigos de Groenewegen (2012), Van den Berg (2012b), e Sabbagh (2016). Agradecemos a um(a) do(a)s pareceristas anônimo(a)s pela indicação da literatura acerca desta rica controvérsia historiográfica.

(15) Hayek, em 1931, publicou um artigo em que afirmou que “...W. Stanley Jevons was hardly overstating the case when he acclaimed it as the cradle of economics, a science that could thus celebrate at the present [1931] the bicentenary of its birth as an independent discipline" (Hayek, 1991, p.246). Seguindo Hayek, autores da escola austríaca têm insistido nesta extrema valorização da obra de Cantillon e do seu lugar na história do pensamento econômico. Murray Rothbard, por exemplo, dá a seu estudo sobre Cantillon o título de "O pai fundador da economia moderna"; por outro lado, vê em Cantillon um "proto-austríaco" (Rothbard, 1995, p. 345).

(16) Cantillon apresenta um pensamento de difícil classificação, uma vez que combina elementos de doutrinas anteriores a ele com antecipações de doutrinas que o sucederiam. Se, por um lado, há aspectos de seu pensamento que ecoam postulados e políticas mercantilistas (associa maior quantidade de dinheiro com maior riqueza do país e valoriza o superávit na balança comercial como um objetivo a ser buscado) (ver Thornton, 2007b), por outro, sua abordagem também revela características fisiocráticas, uma vez que dá mais destaque à terra do que ao trabalho como fonte de riqueza, desenvolvendo, inclusive, uma "teoria do valor-terra" (Brewer, 1988). Além disso, antecipou, em grande medida, a análise do fluxo circular que Quesnay formalizaria em seu famoso Tableau Economique. Cantillon também antecipou ainda elementos da Economia Política Clássica Britânica: é certo que Smith, que, aliás, o citou, sofreu alguma influência de sua obra. É interessante assinalar que Cantillon valorizava sobremaneira o funcionamento do mercado e manifestava grande desconfiança com relação às intervenções do Estado. É exatamente esta dificuldade de classificação que o torna um pensador tão enigmático na história das ideias econômicas. 
Ainda que fosse desejável, uma extensa exegese da obra de Cantillon excede sobremaneira os limites desse artigo ${ }^{17}$. O esforço visará somente identificar a origem dos elementos teóricos que podem ser associados a uma visão monetária heterodoxa para os padrões atuais. Suas reflexões permitiram grandes avanços na identificação de repercussões monetárias sobre o lado real da economia. O elemento mais relevante para o presente trabalho se encontra na análise dinâmica que Cantillon fez acerca dos efeitos monetários sobre a economia, adotando como método a visualização das mudanças dos preços relativos.

Antes de tratarmos especificamente deste tema, no entanto, vale a pena examinar brevemente a descrição lógica que Cantillon faz do nascimento do mercado e da necessidade de moeda, para que se compreenda sua visão sobre o tema. Deve-se ter em mente que ele escreveu numa época em que ainda predominavam as propriedades feudais, de forma que sua análise se concentrava na produção advinda do campo (Rothbard, 1995, p. 348). Dessa forma, o autor franco-irlandês inicia sua análise econômica supondo que o mundo inteiro consiste em uma única propriedade de imensa extensão. Nesse cenário, a produção é uma função das preferências do proprietário monopolista, o qual distribui as tarefas a todos os integrantes da comunidade $^{18}$.

Em seguida, Cantillon altera uma hipótese de seu modelo, assumindo agora que o proprietário faz um loteamento de sua terra para diversos produtores. A partir desse momento, o proprietário perde o poder de alocar os indivíduos em conformidade com seus desejos. Os produtores devem, nessa nova configuração, trocar seus produtos uns com os outros, constituindo um incipiente mercado de negócios. Nasce então a economia de mercado livre, com concorrência entre produtores de um mesmo bem, comércio e um sistema de preços. O dinheiro nasce das trocas como uma mercadoria que atende às funções de meio de troca e de medida de valor (ver Thornton, 2007b, p. 421-425, para uma contextualização histórica deste conceito).

Entendia-se que a quantidade de moeda era definida pelo montante de moedas metálicas de ouro e prata. Depósitos bancários e notas emitidas pelos bancos não eram considerados parte do agregado monetário. Assim como para os clássicos, para ele a moeda tinha a serventia única de facilitar as trocas no mercado. Portanto, a velocidade de circulação

(17) É notável a abrangência dos temas de que Cantillon tratou, muitas vezes de forma pioneira, a saber: teoria do valor, papel do empresário, importância da incerteza, economia espacial, teoria da população, teoria monetária, teoria dos ciclos, comércio internacional, o chamado "species-flow mechanism" que seria depois mais sistematizado por David Hume (para mais detalhes, ver Bordo, 1983, p. 244-247; Van den Berg, 2012b; Murphy, 2014, cap. 4). Adicionalmente, Thornton (2007a) oferece evidências de que Cantillon teria se antecipado a David Ricardo no que toca o conceito de "custo de oportunidade" na área de comércio internacional.

(18) Em outros termos, a produção depende do perfil de demanda do "proprietário monopolista". É no mínimo curioso que Cantillon tenha lançado mão desta representação simplificada do mercado e da economia. Uma questão importante a ser pesquisada futuramente diz respeito a este expediente adotado por Cantillon que parece ser um precursor do uso de "artefatos analíticos" que posteriormente marcaria sobremaneira a economia neoclássica, tal como o "leiloeiro walrasiano" ou o "agente representativo". Agradecemos a um(a) do(a)s pareceristas anônimo(a)s por levantar este ponto muito interessante. 
da moeda e a demanda por moeda eram determinadas fundamentalmente pela extensão do mercado de produtos agrícolas.

Se por um lado há concordância entre Cantillon e os escritos posteriores dos economistas clássicos sobre a função da moeda na realização das trocas, por outro é possível dizer que há uma distinção no tratamento dos preços. Nosso autor diz que "valor intrínseco de uma coisa tem como medida a quantidade de terra e de trabalho que entram na sua produção, levando-se em conta a qualidade ou rendimento da terra e a qualidade de trabalho". Em seguida, no entanto, ele assinala que "ocorre frequentemente que várias coisas que atualmente têm valor intrínseco não se vendem no mercado segundo este valor: isto dependerá do capricho e das fantasias dos homens, e do consumo que farão" (Cantillon, 2002, p. 34). Até aqui, estamos muito próximos da distinção smithiana entre "preço natural" e "preço de mercado". No entanto, Cantillon não trata o "valor intrínseco" como um preço de longo prazo, de equilíbrio, como fariam depois Smith e seus sucessores com o "preço natural"; é razoável concluir, portanto, como faz Rothbard, que ele estava mais preocupado com a compreensão da formação dos preços no mundo real do que com a formação do "preço natural" de longo prazo. A citação feita acima, que relaciona as variações dos preços de mercado com "o capricho e as fantasias dos homens" permite ainda dizer que ele dá à demanda um lugar central na determinação dos $\operatorname{preços}^{19}$.

Na realidade, o autor franco-irlandês atribui ao "valor intrínseco" um papel muito importante na determinação dos preços de mercado, como podemos ver pelo parágrafo:

O valor intrínseco das coisas nunca varia ${ }^{20}$, mas a impossibilidade de estabelecer uma proporção entre a produção de mercadorias e gêneros e o seu consumo num país, provoca uma variação diária e um fluxo e refluxo contínuo nos preços de mercado. Entretanto, nas sociedades bem reguladas, os preços de mercado dos gêneros e mercadorias cujo consumo é constante e uniforme não se afastam muito de seu valor intrínseco. Desde que não sobrevenham anos nem de demasiada escassez nem demasiado abundantes ${ }^{21}$, os magistrados das cidades podem fixar o preço de mercado de muitas coisas, como do pão e da carne, sem que ninguém tenha do que reclamar (Cantillon, 2002, p. 35).

Os metais em geral e, em particular, a prata e o ouro também têm, para Cantillon, da mesma forma que as outras mercadorias, um "valor intrínseco ou real", "proporcional à terra e ao trabalho necessários à sua produção", e um "valor no mercado"22 que "oscila tanto para cima quanto para baixo do seu valor intrínseco e, dependendo do consumo, varia na proporção de sua abundância ou escassez".

(19) Este ponto é igualmente destacado por Rothbard (1995, p. 349-350).

(20) Esta afirmação surpreendente lança luz sobre o que talvez seja a maior debilidade do quadro teórico de Cantillon: ele não deu nenhuma atenção às possibilidades de progresso técnico.

(21) A menção à abundância mostra que Cantillon não se preocupava apenas com a demanda, como diz Rothbard, mas que se preocupava igualmente com a oferta e, portanto, com as condições de produção.

(22) Aqui Cantillon não usa o termo "preço de mercado", embora o sentido seja, claramente, análogo. A razão provavelmente é que como o ouro e a prata são dinheiro, e o dinheiro é usado para expressar os preços, falar em "preço" destes metais não teria sentido. 
Para Cantillon, como vimos, a forma relevante de dinheiro consiste no ouro e na prata (e, eventualmente, outros metais). Ele reconhece a existência de emissões de papel-moeda por parte dos bancos e do governo; mas, ressaltando que essas notas estão lastreadas pela quantidade de metais existente na economia, trata estas emissões como levando ao aumento da velocidade de circulação da moeda, e não como criação de moeda (Cantillon, 2002, p. 169172).

Entrando especificamente na sua análise dos efeitos de um aumento na quantidade de dinheiro, podemos começar dizendo que é verdade que o autor franco-irlandês usou a abordagem quantitativista. No entanto, como reconhece Bordo (1983, p. 237), o uso que Cantillon fez desta abordagem foi singular, dando ênfase tanto às inter-relações entre os componentes da equação de trocas quanto à dinâmica de ajustamentos, em resposta a variações na quantidade de moeda, dos preços relativos e do mercado dos bens em nível desagregado.

Cantillon assinala, por exemplo, em forte contraste com a TQM, que o aumento na quantidade de moeda pode levar ao aumento na sua velocidade de circulação. Sua maior originalidade, no entanto, está na análise do processo de injeção de moeda na economia ${ }^{23}$. Indaga de que forma e em que proporção um aumento na quantidade de moeda afeta os preços, desvinculando-se de uma explicação mecânica tal qual era costume se fazer na tradição quantitativista. Sua análise começa admitindo que uma maior quantidade de moeda exerça pressão sobre os preços, mas prossegue assinalando que é preciso ir além disso:

Todo mundo concorda que a abundância de dinheiro, ou o aumento de sua quantidade nas trocas, provoca o encarecimento de todas as coisas. A quantidade de prata que se levou da América para a Europa nos últimos dois séculos confirma esta verdade.

Locke enuncia como máxima fundamental que a proporção entre a quantidade de gêneros e de mercadorias e a quantidade de dinheiro serve de referência aos preços de mercado. Procurei esclarecer esta sua ideia nos capítulos precedentes. Ele se deu conta de que a abundância de dinheiro encarecia todas as coisas, mas não procurou descobrir como isto se dava. A grande dificuldade em descobrir este processo reside em saber por que via e em que proporção o aumento da quantidade de dinheiro provoca a elevação dos preços das coisas (Cantillon, 2002, p. 99-100).

Ou seja, com mais moeda na economia, os preços aumentarão. Mas seria válido postular que todos os preços serão afetados na mesma intensidade? Cantillon avalia que não, e argumenta que o único caso em que os preços poderiam ser afetados uniformemente seria na condição da existência de pontos de injeção imutáveis; isto é, haveria um conjunto limitado de agentes que fariam circular os montantes adicionais de moeda.

Concluo, pois, que o aumento da quantidade de dinheiro efetivo num país acarreta sempre um aumento no consumo e cria hábitos de gastos maiores. Mas o encarecimento que este

(23) Como destacou um estudioso da obra de Cantillon: "One of the superb features of Cantillon's Essai is that he was the first [...] to understand that money enters the economy as a step-by-step process and hence does not simply increase or raise prices in a homogeneous aggregate. (...) In short, an increased money supply is not supposed to cause [uniform proportionate] changes in the relative prices of the various goods" (Rothbard, 1995, p. 355). 
dinheiro provoca não atinge igualmente todas as espécies de gêneros e mercadorias na mesma proporção da quantidade de dinheiro, a menos que este incremento penetre pelos mesmos canais de circulação que o dinheiro primitivo. Ou seja, a menos que aqueles que ofereciam nos mercados uma onça de prata sejam os mesmos e os únicos que agora oferecem duas onças, quando a quantidade de dinheiro em circulação se duplica, o que nunca ocorre (Cantillon, 2002, p. 108-109) ${ }^{24}$.

É preciso, portanto, examinar o que acontece a partir das diversas formas de entrada de dinheiro na economia ${ }^{25}$. Façamos então uma esquematização do que posteriormente denominou-se na literatura de "Efeito Cantillon".

Cantillon começa focando sua atenção na variação na quantidade de metais a partir de minas de extração de ouro e prata (Cantillon, 2002, p. 99-101).

Quando se descobrem minas de ouro e prata num país e delas se extraem quantidades consideráveis destes minérios, o proprietário destas minas, os empresários e todos aqueles que nelas trabalham aumentarão suas despesas proporcionalmente às riquezas e lucros que obtiverem. Além do mais, emprestarão, a juros, o dinheiro que ultrapassar aquilo de que necessitam para suas despesas.

Todo este dinheiro - tanto o que foi emprestado quanto o que foi despendido - entrará na circulação e fará com que se eleve o preço dos gêneros e das mercadorias em todos os canais da circulação onde ele penetrar (Cantillon, 2002, p. 99).

Mais adiante, nosso autor chama a atenção para a existência de perdedores e ganhadores em termos de rendimentos (Cantillon, 2002, p. 101). Entre os perdedores, estariam proprietários de terra, que teriam de despedir trabalhadores e reduzir despesas. Manufaturas seriam arruinadas, trabalhadores teriam de buscar emprego em outros países, e o número de habitantes do país diminuiria. Assim, os indivíduos ou grupos que receberem inicialmente o dinheiro adicional elevarão seus gastos proporcionalmente aos seus ganhos, de onde se deduz que:

Por conseguinte, eles darão mais emprego a inúmeros artesãos que, tendo muito mais serviço do que tinham anteriormente, aumentarão, pela mesma razão, também as suas despesas. (...) As altercações do mercado ou a demanda de carne, vinho, lã, etc., sendo maior do que comumente, farão com que os preços se elevem. Estes altos preços levarão os arrendatários a decidir-se a usar mais terras para produzi-los para o próximo ano. Estes mesmos arrendatários lucrarão com estes aumentos dos preços e aumentarão as despesas das suas famílias, tal como os demais (Cantillon, 2002, p. 101).

(24) A tradução brasileira continha, neste parágrafo, diversos erros, que foram corrigidos.

(25) As sete fontes que alimentam a economia com novo dinheiro são: (1) a residência de embaixadores e viajantes, os quais trariam novos contingentes monetários; (2) "reparações por violência", que podem ser entendidas como ressarcimento por danos materiais e físicos; (3) transferências líquidas de outros países, tais como doações; (4) imigração de famílias estrangeiras; (5) há entrada de ouro e prata como resultado de trocas comerciais com outros países; (6) entradas de capitais; e (7) a descoberta e/ou a exploração de novas jazidas de ouro ou prata. (Bordo, 1983, p. 242; Cantillon, 2002, p. 100-116). 
Se há, por um lado, a possibilidade de ganho para alguns produtores, de outro, alguns indivíduos serão afetados negativamente. A razão para isso se encontra no efeito progressivo do aumento nos preços. Alguns bens são de consumo geral dos membros de uma sociedade. Entretanto, nem todos os indivíduos recebem no instante inicial um acréscimo proporcional em seu poder de compra. Os preços desses bens se elevam e, como resultado, reduzem a parcela do produto social comandada pelos indivíduos que não tiveram sua renda acrescida. Adicionalmente, produtores de alguns mercados sofrerão com o deslocamento da demanda para outros mercados, os quais, em virtude ao aumento dos preços de seus produtos, passam a exigir um montante de dinheiro maior para a circulação de suas mercadorias. Os produtores negativamente afetados deverão ajustar sua produção às condições existentes, em termos de desemprego de fatores de produção, especialmente a mão-de-obra. Por fim, há também os proprietários de terra e os trabalhadores em geral que recebem rendimentos nominais, fixados por um período determinado de tempo.

Portanto, quem sofrerá com este encarecimento e com este aumento do consume serão, primeiro, os proprietários de terra durante a vigência de seus arrendamentos, depois, seus criados e todos os trabalhadores ou pessoas que sustentam suas famílias com ganhos fixos. Todos estes terão de que reduzir suas despesas na proporção do novo consumo, o que obrigará que grande parte deles seja obrigada a deixar o país e a ir tentar a sorte alhures. (...) Eis aí, mais ou menos, como um aumento considerável da quantidade de dinheiro devido às minas faz crescer o consumo e, ao fazer diminuir o número de habitantes do país, provoca um dispêndio maior entre os que ficam (Cantillon, 2002, pp. 100-101).

Se a extração de prata continuar por um tempo suficiente, os proprietários e outros setores inicialmente prejudicados aumentarão seus preços. Aumentarão os preços em geral, mas haverá déficit na balança comercial, de forma que o ouro e a prata irão para outros países.

Isto empobrecerá imperceptivelmente este país e o tornará, de algum modo, dependente do país estrangeiro ao qual ele é obrigado a enviar anualmente a prata que extrai das minas. A grande circulação do dinheiro que, de início, era geral, cessa; a pobreza e a miséria aparecem e a exploração das minas parece fazer-se exclusivamente em benefício dos que nelas trabalham e dos estrangeiros que delas tiram proveito (Cantillon, 2002, p. 102).

Contrastando com o caso anterior, se o aumento da quantidade de dinheiro provém de uma balança comercial favorável (que provoca a entrada de metais preciosos, isto é, de dinheiro), o efeito para o país será muito mais positivo, embora, ainda assim, seja impossível impedir que em longo prazo a balança comercial se torne desfavorável e comece um período de declínio (Cantillon, 2002, p. 102-104).

Brewer (1988, p. 455-456) sistematiza a análise feita por Cantillon das vantagens do aumento da quantidade de dinheiro a partir do superávit da balança comercial. A ideia geral é que "os fatores que geram o excedente (...) permitem ao país em questão manter uma posição forte mesmo se os preços sobem" (p. 455), e por mais tempo. Em primeiro lugar, como o dinheiro adicional é recebido por comerciantes, empresários e trabalhadores (e não por proprietários de terras ou de minas), é provável que haja maior aumento da poupança para 
comprar terras, o que adia o aumento dos preços. Em segundo lugar, pode levar bastante tempo para que os concorrentes possam deslocar os produtores do país que teve o excedente comercial, já que os bens exportados são produtos diferenciados, as habilidades para produzir são difíceis de adquirir, o país se beneficia de boa reputação como produtor, e os canais comerciais são difíceis de penetrar. Por um tempo razoável, o país superavitário poderá manter sua posição, e beneficiar-se de termos de troca mais favoráveis.

Cantillon acrescenta ainda que "se este país é marítimo, a facilidade e os bons preços com que transporta seus produtos para os demais países poderão ser de molde a compensar a carestia do trabalho que o dinheiro excessivo acarreta" (Cantillon, 2002, p. 103-104). Como exemplo de um país que tem esta vantagem, Cantillon cita a Inglaterra: "Ainda que na Inglaterra o trabalho seja muito caro, devido à abundância de dinheiro, a superioridade de sua marinha permite-lhe vender seus produtos por preços mais razoáveis do que a França, onde estes mesmos produtos são mais baratos" (Cantillon, 2002, p. 104). Logo, esta vantagem prolonga mais ainda o período de prosperidade.

Retomando a análise em um capítulo seguinte, Cantillon reexamina a questão de quais agentes teriam seu poder de compra aumentado, em quais tipos de bens este maior poder de compra seria utilizado, e como variaria a oferta destes bens ${ }^{26}$. Seu raciocínio pode ser resumido da seguinte maneira: o dinheiro será colocado em circulação e gerará disponibilidade adicional de gasto, a qual, por sua vez, traduz-se em potencial de demanda por bens. A natureza dessa demanda será definida pelos gostos e preferências dos indivíduos e dos grupos que receberão esse dinheiro, assim como a elasticidade-renda dos bens por eles desejados. A rede de relacionamentos comerciais de cada um desses indivíduos corresponderá à sequência de agentes que o dinheiro novo vai percorrer quando colocado em circulação por meio do consumo ou por meio do empréstimo. Em decorrência, a intensidade com que o preço de cada bem da economia será afetado fica condicionada à sequência de agentes que esse dinheiro percorrerá.

A carestia, que o aumento da quantidade de dinheiro introduz no país, vai depender do ritmo que este dinheiro imprimirá ao consumo e à circulação. Por quaisquer mãos que passe o dinheiro que foi introduzido, naturalmente ele fará aumentar o consumo, mas este consumo será maior ou menor, conforme o caso. Certamente que ele recairá mais sobre algumas mercadorias ou gêneros do que sobre outros, segundo o capricho dos que detêm o dinheiro (Cantillon, 2002, p. 107).

Após identificar como o dinheiro novo afetará a formação da demanda, resta verificar a restrição imposta à satisfação da mesma, a saber, a elasticidade da oferta dos bens afetados. As condições de oferta serão também definidas, nesse esquema, pela existência de barreiras comerciais e custos de transporte.

(26) Bordo traduz esta análise numa linguagem moderna dizendo que o dinheiro novo afetará os preços das diversas mercadorias dependendo (1) do tipo de agente que recebe o dinheiro novo; (2) de em quais bens esse montante será gasto; e (3) da elasticidade da oferta dos produtos afetados (Bordo, 1983, p. 242). 
[...] o que, em geral, encarece relativamente mais a carne do que o pão é o fato de que, comumente, os países permitem a livre entrada de trigo de países estrangeiros, mas proíbem absolutamente a entrada de bois, como ocorre na Inglaterra, que cobra, assim como outros países, direitos de importação bastante altos (Cantillon, 2002, p. 105).

O que se deduz desse modelo é, portanto, que a elasticidade da oferta será um parâmetro chave na determinação da intensidade da elevação do preço de um determinado bem. Ou seja, dado um aumento na quantidade de moeda, alguns bens terão sua demanda acrescida. A satisfação dessa demanda fica condicionada à possibilidade dos produtores de atender à mesma, a qual está sujeita aos custos e técnicas de produção e à escassez dos insumos que participam do processo de produção dos bens em questão.

Assim, devem ser diferenciados os dois mecanismos atuantes a partir do impulso inicial dado, nesse caso, pelo aumento na quantidade de dinheiro circulante. Um deles é o efeito direto que se manifesta, na terminologia moderna, no deslocamento para a direita da curva de demanda dos produtos afetados, pressionando os preços dos produtos dentro dos limites especificados pelas técnicas produtivas e pela escassez de insumos. O segundo é um mecanismo indireto que se expressa nos efeitos sobre os outros setores da economia, os quais não são afetados diretamente pelo gasto adicional. Um exemplo de setores que são afetados indiretamente é o conjunto de setores que produzem matérias-primas, o chamado setor intermediário da economia. Esses ramos sofrem as pressões quando se esgotam os estoques dos setores de bens de consumo final, os quais passam a demandar mais insumos produtivos. A esses aumentos na demanda dos diversos bens segue-se uma sequência de ajustamentos nos respectivos setores em termos de emprego, produto real e lucros.

Comentando a parte desta análise relativa às variações de preços relativos, Michael Bordo (1983, p. 241) diz que Cantillon admitia a possibilidade de prevalecer a neutralidade da moeda a longo prazo (referindo-se à possibilidade de variação proporcional nos preços e à ausência de efeitos reais duradouros a partir de um aumento na quantidade de moeda), mas achava isto improvável. De fato, Cantillon vai além: diz, como vimos, que "isto nunca ocorre". Mais ainda: quando consideramos os outros aspectos da análise, fica evidente que Cantillon chama claramente a atenção para a existência de "efeitos reais" duradouros (embora variáveis ao longo do tempo: ele chama a atenção para períodos de ascensão e de declínio das nações).

Cantillon considera também os efeitos diferentes das diversas formas de entrada de dinheiro sobre as taxas de juros. Ao entrar na economia, o dinheiro novo pode ser emprestado para terceiros ou pode ser gasto em consumo de bens no mercado; ou, ainda, pode ser em parte consumido e ter o restante emprestado a terceiros.

Para Cantillon, a taxa de juros era determinada no mercado de crédito, em resposta a variações na quantidade de moeda:

O preço das coisas é estabelecido nas altercações do mercado pela proporção entre a quantidade de coisas expostas para a venda e a quantidade de dinheiro que por elas se oferece ou, o que é a mesma coisa, pela proporção numérica entre vendedores e 
compradores. Do mesmo modo, os juros do dinheiro se estabelecem pela proporção numérica entre os que pedem e os que oferecem empréstimos de dinheiro (Cantillon, 2002, p. 118).

A partir desta colocação, a destinação dos recursos adicionais para consumo e empréstimo adquire significância no quadro analítico do autor franco-irlandês. Os efeitos desse aumento na quantidade de moeda são definidos de acordo com o grupo de indivíduos que recebe o dinheiro novo, isto é, se são consumidores (spenders) ou emprestadores (lenders):

Se a abundância de dinheiro num país vem pelas mãos daqueles que o emprestam, ela levará, sem dúvida, à redução dos juros correntes, ao aumentar o número daqueles que oferecem tais empréstimos. No entanto, se esta abundância tem origem naquelas pessoas que o gastam, ocorrerá exatamente o oposto, pois ela fará com que os juros subam, ao aumentar o número daqueles empresários que terão que trabalhar em meio a este aumento de despesa e que terão de pedir empréstimos para poder equipar suas empresas arcando com as mais diferentes taxas de juros (Cantillon, 2002, p. 125).

Assim, se o dinheiro novo chegar inicialmente às mãos dos emprestadores, esses incrementarão a oferta de crédito e reduzirão temporariamente a taxa de juros, possibilitando o aumento do investimento. Bordo (1983, p. 247) chega a atribuir a Cantillon a antecipação da distinção entre o efeito liquidez de curto prazo e o efeito renda de longo prazo decorrentes de variações na taxa de juros ${ }^{27}$.

Conclui-se, portanto, que o efeito final de uma elevação na quantidade de moeda será o aumento dos preços. Entretanto, o processo gradual pelo qual esse aumento ocorre provoca uma série de ajustamentos na economia, em termos do emprego dos fatores de produção, de lucros, de taxa de juros e, subsequentemente, do gasto destinado a consumo e investimento. Na análise dinâmica de Cantillon, não se pode tomar como dado o processo de ajuste, tal como é feito pela abordagem quantitativista mecânica ao assumir que os preços "eventualmente" aumentam na mesma proporção em que a quantidade de moeda.

\section{Considerações finais}

Procuramos mostrar neste trabalho que, em sua economia monetária, Richard Cantillon adota pontos de vista que correspondem, hoje, a visões heterodoxas da moeda. Ainda que ele parta da Teoria Quantitativa da Moeda (com referência fundamentalmente em Locke), sua análise segue uma direção que se afasta das características centrais desta abordagem.

Ele mostrou que as diversas formas de introdução da moeda no sistema econômico têm implicações diferentes sobre os preços relativos e sobre as taxas de juros (o "Efeito Cantillon").

(27) Nas palavras de Bordo (1983, p. 248): "In the short-run, the new money may be spent or lent, to the extent it is lent it will lower the interest rate (the liquidity effect); to the extent it is spent [it] will stimulate production and raise the demand for loanable funds. It is assumed (in the literature) that the liquidity effect initially dominates. Ultimately, the increased expenditure further induced by the fall in the interest rate will ensure that the demand for loanable funds will rise (and the income effect dominates)". 
André Roncaglia de Carvalho, João Machado Borges Neto

A partir daí, toda a evolução da economia segue caminhos distintos (como fica claro, por exemplo, na sua comparação entre as consequências de um país possuir minas de ouro ou prata ou superávit na balança comercial).

Tudo isto (alterações de preços relativos, de taxas de juros, e, obviamente, do andamento geral da economia) são, usando a linguagem moderna, "efeitos reais" da moeda. E Cantillon, embora preveja, em certas condições, um comportamento cíclico (de longo prazo) da economia, não prevê nenhuma tendência ao equilíbrio que pudesse ser interpretada como a recuperação de uma mesma situação "real" em longo prazo. Ou seja, não há nada que possa ser interpretado como uma conclusão típica da atual ortodoxia em matéria monetária, ou seja, a da neutralidade da moeda.

O que confere interesse em chamar a atenção para os aspectos da economia monetária de Cantillon que hoje são considerados heterodoxos, é o fato de eles estarem associados, como examinamos neste trabalho, a alguns dos aspectos mais modernos da economia Cantillon, prescientes que foram de inúmeros desenvolvimentos teóricos posteriores.

\section{Referências bibliográficas}

BLANCHARD, Olivier. Discussion of "Price level, relative prices and economic stability: aspects of the interwar debate" by David Laidler. In: LAIDLER, David. The price level, relative prices and economic stability: aspects of the interwar debate. p. 24-28. Sept. 2006. (BIS Working Papers, n. 136). Disponível em: www.bis.org. Acesso em: 12 dez. 2006.

BLAUG, Mark. História do pensamento econômico (tradução da $4^{\mathrm{a}}$ edição inglesa de Economic Theory in Retrospect). Lisboa: Publicações Dom Quixote, 1989.

BLAUG, Mark. Why is the quantity theory of money the oldest surviving theory in economics? In: BLAUG, Mark (Org.). Quantity theory of money from Locke to Keynes and Friedman. Hants, England: Edward Elgar Pulishing Limited, 1995. p. 27-49.

BLAUG, Mark. Great economists since Keynes: an introduction to the lives and works of one hundred modern economists. 2. ed. Cheltenham: Edward Elgar, 1998.

BORDO, M. D. The monetary economics of Richard Cantillon. Journal of Monetary Economics, n. 12, p. 235-258, 1983.

BREWER, Anthony. Cantillon and the Land Theory of Value. History of Political Economy, v. 20, n. 1, p. 1-14, 1988a.

BREWER, Anthony. Cantillon and mercantilism. History of Political Economy, v. 20, n. 3, p. 447-460, 1988 b.

BREWER, Anthony. Richard Cantillon: pioneer of economic theory. London and New York: Routledge, 1992. 
A economia monetária de Cantillon e o debate moderno entre ortodoxia e heterodoxia

CANTILLON, Richard. Essai sur la nature du commerce en général. Ed. by Henry Higgs. New York: Augustus M. Kelley, [1734] 1931. (Reprints of Economic Classics).

CANTILLON, Richard. Ensaio sobre a natureza do comércio em geral (1755). Curitiba: Segesta Editora, 2002.

ELTIS, Walter. John Locke, the quantity theory of money and the establishment of a sound currency. In: BLAUG, Mark. Quantity theory of money from Locke to Keynes and Friedman. Hants, England: Edward Elgar Pulishing Limited, 1995. p. 4-26.

FISHER, Irving. The purchasing power of money: its determination and relation to credit interest and crises. New York: A. M. Kelley, 1963.

FRIEDMAN, Milton. The lag in effect of monetary policy. Journal of Political Economy, v. 69 , n. 5 , p. 447-466, Oct. 1961.

FRIEDMAN, Milton; SCHWARTZ, A. J. A monetary history of the United States, 1867-1960. Princeton University Press, 1963.

GROENEWEGEN, Peter. A new English translation of Cantillon: modern improvement or anachronistic rendition into North American English? History of Economics Review, v. 55, n. 1, p. 80-89, 2012. DOI: 10.1080/18386318.2012.11682195.

HAYEK, F. [1931]. Prices and production. 2. ed. London: Routledge, 1935.

HAYEK, F. Richard Cantillon (c. 1680-1734). The Journal of Libertarian Studies, v. 7, p. 217-247, Fall 1985. Citado a partir da sua republicação como capítulo em HAYEK. The trend of economic thinking. Chicago: The University of Chicago Press, 1991 [Tradução do original alemão de 1931, publicado como introdução da tradução alemã do Ensaio].

JEVONS, W. Stanley. Richard Cantillon y la nacionalidad de la economía política. [Tradução em espanhol de Richard Cantillon and the nationality of political economy. Contemporary Review, v. 39. Jan. 1881.] In: CANTILLON, Richard. Ensayo sobre la naturaleza del comercio en general. México: Fondo de Cultura Económica, 1950.

KEYNES, J. M. A treatise on money. v. 1 e 2. Reproduzidos em KEYNES, J. M. The collected writings of J. M. Keynes. Ed. by D. Moggridge. London: Macmillan, [1930] 1973. v. 7.

KIYOTAKI, Nobuhiro. Discussion of "Price level, relative prices and economic stability: aspects of the interwar debate" by David Laidler. In: LAIDLER, David. The price level, relative prices and economic stability: aspects of the interwar debate. Sept. 2006. (BIS Working Papers, n. 136). Disponível em: www.bis.org. Acesso em: 12 dez. 2006. p. 29-31.

LAIDLER, David. The golden age of the quantity theory: the development of neoclassical monetary economics 1870-1914. London: Philip Allan, 1991. 
André Roncaglia de Carvalho, João Machado Borges Neto

LAIDLER, David. The price level, relative prices and economic stability: aspects of the interwar debate. Sept. 2006. (BIS Working Papers, n. 136). Disponível em: www.bis.org. Acesso em: 12 dez. 2006.

MILL, John Stuart. Principles of political economy with some of their applications to social philosophy. 6. ed. London: Longmans, Green, Reader \& Dyer, 1888.

MISES, Ludwig von. On manipulation of money and credit. New York: Free Market Books, 1978.

MURPHY, Antoin. Richard Cantillon: an Irish Banker in Paris. Hermathena, n. 135, p. $45-$ 74, 1984.

MURPHY, Antoin. Richard Cantillon: entrepreneur and economist. Oxford: Clarendon Press, 1986.

MURPHY, Antoin. The genesis of macroeconomics: new ideas from Sir William Petty to Henry Thornton. 2. ed. New York: Oxford University Press, 2014.

MYRDAL, Gunnar [1932]. Monetary equilibrium. 3. ed. New York: Sentry Press, 1965.

MOLLO, M. L. R. Ortodoxia e heterodoxia monetárias: a questão da neutralidade da moeda Revista de Economia Política, v. 24, n. 3 (95), jul./set. 2004.

PATINKIN, Don. Money, interest and prices: an integration of monetary and value theory. 2. Ed. New York: Harper \& Row, 1965.

PATINKIN, Don. Neutrality of money. In: EATWELL; MILGATE; NEWMAN (Ed.). The New Palgrave - Money. London: Macmillan, 1989. p. 273-287.

PATINKIN, Don. Concluding comments on the quantity theory. In: BLAUG, Mark. Quantity theory of money from Locke to Keynes and Friedman. Hants, England: Edward Elgar Pulishing Limited, 1995. p. 120-133.

PIGOU, A. C. [1927]. Industrial fluctuations. 2. ed. London: Macmillan, 1929.

ROBERTSON, D. H. [1926]. Banking policy and the price level. 2. ed. New York: Kelley, 1949.

ROTHBARD, Murray. The founding father of modern economics: Richard Cantillon. In: ROTHBARD, Murray. An Austrian perspective on history of economic thought: economic thought before Adam Smith. Brookfield: Edward Elgar, 1995. v. I.

SABBAGH, Gabriel. Cantillon in French and English. Two editions by Richard Van Den Berg and Antoin E. Murphy: new facts and hypotheses. Contributions to Political Economy, v. 35, n. 1, p. 91-125, 2016. 
A economia monetária de Cantillon e o debate moderno entre ortodoxia e heterodoxia

SOROMENHO, Jorge Eduardo de Castro. Estudo sobre as origens da crítica de Hayek ao conceito de equilíbrio. Tese (Doutorado)-Faculdade de Economia, Administração e Contabilidade da Universidade de São Paulo, 1994.

THORNTON, Henry [1802]. An enquiry into the nature and effects of the paper credit of Great Britain. Ed. by F.A. Hayek. London: George Allen \& Unwin, 1939.

THORNTON, Mark. Richard Cantillon and the discovery of opportunity cost. History of Political Economy, v. 39, n. 1, p. 97-119, 2007a.

THORNTON, Mark. Was Richard Cantillon a mercantilist? Journal of the History of Economic Thought, v. 29, n. 4, p. 417-435, Dec. 2007b.

WHITE, William. Is price stability enough? Apr. 2006. (BIS Working Papers, n. 205). Disponível em: www.bis.org. Acesso em: 12 dez. 2006.

WICKSELL, Knut [1898]. Interest and prices: a study of the causes regulating the value of money. Tradução para o inglês de R. F. Kahn. New York: A.M. Kelley, 1965.

WICKSELL, Knut. Lições de economia política. Trad. de Maria Beatriz de Albuquerque David. 2. ed. São Paulo: Nova Cultural, 1988. (Coleção Os Economistas). (Originalmente v. I de 1902 e v. II de 1906).

VAN DEN BERG, R. Richard Cantillon's early monetary views? Economic Thought, v. 1, n.1, p. 48-79, 2012a. Disponível em: http://et.worldeconomicsassociation.org/papers/richardcantillons-early-monetary-views/.

VAN DEN BERG, R. Something wonderful and incomprehensible in their oeconomy: the English versions of Richard Cantillon's essay on the nature of trade in general. European Journal of the History of Economic Thought, v. 19, n. 6, p. 868-907, Dec. 2012b. 